\title{
Eosinophilic Metamyelocyte Count
}

National Cancer Institute

\section{Source}

National Cancer Institute. Eosinophilic Metamyelocyte Count. NCI Thesaurus. Code C84819.

The determination of the number of eosinophilic metamyelocytes in a blood sample. 